\title{
Lo práctico en lexicografía y la práctica lexicográfica. A propósito de dos nuevos diccionarios abreviados: El DeA(A) y el Due(A)
}

\author{
Humberto Hernández \\ Universidad de La Laguna
}

\section{INTRODUCCIÓN}

Una de las críticas más frecuentes de la que suelen ser objeto los diccionarios está relacionada con la cantidad de información que estas obras contienen. El usuario común, no especializado, centra su atención en la nomenclatura: un diccionario es mejor o peor según registre un mayor o menor número de entradas; por su parte, los usuarios críticos cualificados se fijan más en cuestiones microestructurales. Los gramáticos, por ejemplo, tienden a considerar como una gran imperfección de los diccionarios la deficiente información morfosintáctica. También echan en falta más información específica los especialistas en historia de la lengua, los fonólogos, los sociolingüistas, los semantistas, los pragmáticos y los dialectólogos; cada uno, por supuesto, exige al diccionario mayor cantidad de datos relacionados con el ámbito de su especialidad. Porque el lexicógrafo -podrían argüir algunos-, dado el estado de desarrollo de las distintas disciplinas lingüísticas, no puede saberlo todo; y, ciertamente, es así, sólo que, en realidad, el reproche no tiene mucho sentido hoy, cuando no hay elaboradores de diccionarios que hagan su trabajo en la más absoluta soledad y sin el asesoramiento de los estudiosos de cada área, de los de las distintas disciplinas lingüísticas y de los de otras ciencias experimentales o humanas.

Si el lexicógrafo, o, mejor, el equipo de lexicógrafos fuera a incluir en cada elemento de la microestructura toda la información que existe para una buena parte de las unidades de la lengua, el resultado sería, en

Humberto Hernández, "Lo práctico en lexicografía y la práctica lexicográfica. A propósito de dos nuevos diccionarios abreviados: El DEA(A) y el DUE(A)", Revista de Lexicografia, VII (2000-2001), pp. 91-110. 
muchos casos, extensas monografías con informaciones tan exhaustivas como de escasa utilidad para el usuario común. Los lexicógrafos actúan seleccionando los datos que consideran pertinentes después de consultar a los distintos especialistas o acudiendo a las obras de referencia fundamentales. La labor lexicográfica, pues, tiene una doble vertiente, una de selección y otra de elaboración: la primera, una vez decidido qué entradas constituirán su macroestructura, consiste en elegir los datos referidos a la unidad léxica en cuanto signo (el primer enunciado según Manuel Seco'), informaciones necesarias sobre todo para los procesos de codificación, y la segunda, la más dificultosa, sin duda, la que se refiere a la elaboración o al mejoramiento de las definiciones (el segundo enunciado de Seco), elementos imprescindibles de la microestructura y de capital importancia para la descodificación y para la codificación.

Sin embargo, frente a esta demanda amplificadora de algunos sectores de destinatarios, los lexicógrafos se ven ante la paradójica opción de la reducción que aconsejan los expertos en marketing de las editoriales tras los resultados de los estudios de mercado realizados con modernas técnicas de consulta, o a razones didácticas perfectamente justificadas; porque si excesivo resulta proporcionar a niños de educación primaria extensos repertorios con una enorme cantidad de información de difícil interpretación para su limitada capacidad de comprensión, inoperante cuando menos es para el ciudadano medio tener que manejar varios y pesados volúmenes plagados de arcaísmos, detallada documentación y abundante información gramatical, sociolectal, dialectal, semántica y pragmática cuando sus necesidades se limitan a la realización de consultas encaminadas a constatar la adecuación de sus escritos a la norma más generalizada y prestigiosa.

1 La distinción entre los dos enunciados en el artículo lexicográfico se encuentra en su trabajo "Problemas formales de la definición" (Seco 1987: 15-34). 


\section{POR QUÉ SURGEN LOS DICCIONARIOS ABREVIADOS}

Se abrevia por dos razones fundamentales: a) para adaptar el contenido de una obra extensa a las necesidades y destrezas de grupos de destinatarios no estandarizados, y b) para ofrecer al mismo grupo de usuarios que a los que se les dirige la versión mayor una variante más ligera y manejable, tanto en cuestiones de formato como en lo relativo al contenido.

En el caso de a), como la reducción implica un cambio de destinatario, el acortamiento afectará a la macroestructura y a la microestructura, pero, sobre todo a esta última: habrá que adaptar, por ejemplo, la forma de proporcionar la información gramatical o el metalenguaje definitorio para adecuarlo a la capacidad de comprensión de los nuevos destinatarios. Es lo que debería hacerse en los casos en que a partir de un diccionario general o de uso se desea elaborar un diccionario escolar; veamos un ejemplo de este tipo de adaptación:

artículo 1$)^{2}$

bacalao s.m. 1 Pez marino comestible, de gran tamaño, cuerpo alargado y cilíndrico y cabeza muy grande; abadejo: El bacalao se puede consumir fresco o curado y en salazón. [ $\mathbf{2} \rightarrow$ bakalao. $\mathbf{3} \|$ cortar el bacalao; $\mathrm{col}$. Mandar o decidir en un asunto o en un grupo: En esta empresa es el subdirector el que corta el bacalao. $\square$ ETIMOL. De origen incierto. $\square$ PRON. Incorr. *[bacaládo]. $\square$ MORF. En la acepción 1, es un sustantivo epiceno: el bacalao macho, el bacalao hembra.

artículo 2)

bacalao [sustantivo masculino] 1 Pez marino comestible, de gran tamaño, que tiene el cuerpo alargado y la cabeza muy grande. $\Theta$ página 697. 2 [expresión] cortar el bacalao Mandar: Aquí quien corta el bacalao soy yo. $\square[$ [La expresión es coloquial].

Obsérvese en este caso en que ha habido una verdadera adaptación, cómo no aparecen abreviaturas ("s.m." y "col." se expresan en su forma completa: "sustantivo masculino" y "coloquial"), ni acepciones poco frecuentes o poco rentables (el caso de "bakalao") u otras informa-

2 El artículo 1) procede del Clave y el 2) del DdeB. 
ciones poco útiles para el estudiante del segundo ciclo de primaria (informaciones etimológica, ortológica y morfológica complementaria).

Veamos estos otros ejemplos:

artículo 3$)^{3}$

bacalao. (De or. inc.; cf. neerl. ant. bakeljauw, variante de kabeljauw) m. Pez teleósteo, anacanto, de cuerpo simétrico con tres aletas dorsales y dos anales, y una barbilla en la sínfisis de la mandíbula inferior. II 2. Carne de bacalao, curado y salado para su conserva.II al pil-pil. Guiso típico del País Vasco que se hace de abadejo, aceite, guindillas y ajos, en cazuela de barro, y se sirve hirviendo.ll de Escocia. El que se pesca entre Escocia e Islandia y es más apreciado que el común. II cortar el bacalao. fr. fig. y fam. Ser el que de hecho manda o dispone en una colectividad o en un asunto.

artículo 4)

bacalao $\mathrm{m}$. Pez teleósteo, anacanto, de cuerpo simétrico con tres aletas dorsales y dos anales, y una barbilla [apéndice carnoso] en la sínfisis [conjunto de partes orgánicas que aseguran la unión de dos superficies óseas] de la mandíbula inferior.ll 2. Carne de bacalao, curado y salado para su conserva.ll cortar el bacalao. fr. fig. y fam. Ser el que de hecho manda o dispone en una colectividad o en un asunto.

Ahora estamos también ante el paso de un diccionario general a uno escolar, sin embargo sólo ha habido supresión de información: desaparece la información etimológica ("De or. inc.; cf. neerl. ant. bakeljauw...") y las expresiones "al pil-pil" y "de Escocia". Las definiciones permanecen igual, con los mismos términos hiperespecíficos ("teleósteo", "anacanto", "sínfisis"), pero se añade una breve explicación, entre corchetes, a las voces con acepciones técnicas o poco frecuentes (barbilla, "Apéndice carnoso") o que no aparecen definidas en el propio diccionario (sínfisis, "Conjunto de partes orgánicas que aseguran la unión de dos superficies óseas"). Desaparecen, así, las pistas perdidas, pero el recurso puede suponer una dificultad añadida para la comprensión de la

3 El artículo 3) procede del DraE y el 4) del DeRA. 
definición por los inexpertos y jóvenes usuarios ${ }^{4}$. Además de este último diccionario que acabamos de comentar hay numerosísimos ejemplos de "jibarización" en la lexicografía escolar de hace apenas una década: los diccionarios escolares de entonces eran, en su mayoría, reducciones inorgánicas de los diccionarios grandes, en especial del de la Academia, y, como podrá suponerse, eran obras de escasa o nula calidad $^{5}$.

En el caso b), cuando la versión abreviada va destinada al mismo grupo de usuarios que a los que se destina la versión extensa, las reducciones no precisan ningún tipo de adaptación. Se suprimen unidades de la macroestructura (voces obsoletas o marcadas) y elementos microestructurales (informaciones que no son imprescindibles para la codificación y para la descodificación) atendiendo a criterios de rentabilidad. Es lo que hizo, por ejemplo, la Real Academia Española al despojar de todo su aparato documental ${ }^{6}$ el Diccionario de Autoridades (17261739) para ofrecerlo en un solo volumen de más fácil manejo. Manuel Alvar Ezquerra se lamentaba de la trascendental decisión académica: "No podían imaginarse los académicos dieciochescos la importancia de su determinación: ahí está el DRAE como consecuencia de aquella resolución, y también, en lo que nos concierne ahora, una tímida ejemplificación en nuestra lexicografía, lo cual contrasta enormemente con la situación de Francia, por mencionar sólo un país con una importante actividad lexicográfica". Aunque, en realidad, a nuestro juicio, no fue

4 En la $2^{\mathrm{a}}$ edición el DERA aligera la definición y procede a realizar una pequeña adaptación, dice así: "Pez teleósteo, anacanto, de cuerpo simétrico con tras aletas dorsales y dos anales, y un apéndice carnoso en la mandíbula inferior".

5 Vid. un panorama de esta lexicografía jibarizada en Humberto Hernández (1989). Para una presentación más resumida y actualizada, véase también H. Hernández (1998a).

6 En realidad, como es bien sabido, esta versión abreviada, origen de los sucesivos diccionarios académicos, fue debida a la urgencia por sacar una nueva edición de Autoridades: ante la demora que hubiera supuesto la elaboración de esa segunda edición (se publicó el primer volumen en 1770), se decidió interrumpir la tarea y publicar todo el dicconario, sin autoridades, en un volumen único.

7 Alvar Ezquerra 1993: 128-129. 
tan grave la decisión de publicar el diccionario sin autoridades, de hecho, ahí está, y ha funcionado - mal para algunas cuestiones, bien para otras- durante más de doscientos años; lo lamentable fue, en todo caso, la falta de continuidad del repertorio en su versión íntegra.

Hay otros ejemplos de abreviaciones sin adaptación hechas con el único fin de conseguir una mayor "manejabilidad"; resultan, así, los "diccionarios portátiles" que aparecen en la lexicografía española en el siglo XIX: el Diccionario de la lengua castellana (París, 1826) compendiado por Cristóval Pla y Torres, o el Diccionario Portátil de la lengua castellana (París, 1873), son algunos ejemplos de reducciones del diccionario académico.

En el año 2000 se publicaron dos buenos ejemplos de diccionarios abreviados: el Diccionario abreviado del español actual [DEA(A)] y el Diccionario de uso del español Abreviado [DuE(A)], en los que encontramos distintos procedimientos de reducción y que vamos a analizar a continuación.

\section{EL DICCIONARIO ABREVIADO DEL ESPAÑOL ACTUAL [DEA(A)]}

El origen del DeA(A) es el Diccionario del español actual (DEA) de Manuel Seco, Olimpia Andrés y Gabino Ramos que publicó en Madrid en 1999 Aguilar Lexicografía del Grupo Santillana de Ediciones. Los destinatarios son, en principio, los mismos que los de la versión grande, pues su objetivo - dice Manuel Seco- es "ofrecer lo más esencial del contenido de esta gran obra en un solo volumen más manejable" (2000: XI).

El contenido del DEA es de unas 75.000 entradas y más de 100.000 acepciones, y su novedad principal está en su profusa documentación con cerca de 200.000 citas extraídas de libros y de publicaciones periódicas. Es, además, un diccionario descriptivo (inventaría el léxico que se usa, no sólo el que se debe usar), sincrónico (los materiales proceden de documentos fechados a partir de mediados del siglo Xx) y del español de España. "Aspiramos aquí a registrar-leemos en "Características del diccionario"- el uso real comprobado de una lengua en un espacio dado y en un período dado". 
Puede decirse, en líneas generales, que para la conversión del DEA en el $\operatorname{DEA}(\mathrm{A})$ no hubo ningún tipo de adaptación y sólo se eliminaron las citas y sus documentaciones; así lo reconoce Manuel Seco en la "Introducción" de esta versión abreviada: "Salvo en algunos escasos retoques, la diferencia entre el diccionario extenso y éste abreviado está en que aquí, para conseguir la necesaria reducción de dimensiones del libro, han sido suprimidos los ejemplos tomados del uso real que, con indicación exacta de su procedencia, seguían en aquel a todas las acepciones y locuciones definidas, demostrando la existencia de cada una de ellas, de su significado y de su uso en la lengua contemporánea. Únicamente en casos muy contados, y por ineludible exigencia de la claridad, hemos puesto breves ejemplos nuestros que aparecen precedidos de un asterisco" (2000: XII).

\subsection{La macroestructura del Dea(A)}

El DeA(A) no abrevia, como acabamos de ver, la nomenclatura del DEA y tiene, en consecuencia, el mismo número de entradas, 75.000, que el repertorio de procedencia.

De los 127 artículos que contiene el DRAE en el tramo b-badén, que hemos tomado como referencia, 55 no están en el DEA(A), diccionario que en este tramo registra 128 artículos (Vid. apéndice).

Están ausentes del DEA(A) variantes ortográficas poco usuales: $b a$ badero, variante de babero; bacallao, variante de bacalao; dialectalismos exóticos: babaidor, en Filipinas "Mujeriego"; babanco, en Salamanca "Persona boba" o babazorro, en Aragón "Joven atrevido y arriscado". Tampoco registra el DEA(A) la voz babatel ("Cualquier cosa desaliñada que cuelga del cuello cerca de la barba"), anticuada como reconoce el DRAE; babequía y baboquía son también anticuadas (ambas significaban "Bobería"), lo mismo que bacada ("Batacazo"). Otros términos ausentes son tecnicismos, o voces muy específicas, que designan realidades que han desaparecido, o que están a punto de desaparecer, como baberol ("Babera de la armadura"), babilar ("En los molinos harineros, eje sobre el que se mueve la canaleja"), o muy alejadas de nuestra cultura y civilización, como, por ejemplo, baalita ("Adorador 
de Baal, divinidad semita"), babirusa ("Cerdo salvaje que vive en Asia..."), babismo ("Sistema religioso fundado en Persia en el siglo XIX...”).

Sin embargo, el DeA(A), con 128 entradas en este tramo, incorpora medio centenar de términos nuevos en relación con el DRAE: variantes frecuentes como babar (de babear) y derivados de uso común del tipo babeante ("Que babea"), babosería ("Cualidad de baboso"). Numerosos neologismos, algunos extranjerismos, como baby ("Bebé"), babysitter ("Canguro"), background ("Conjunto de conocimientos o experiencias que constituyen el bagaje intelectual de una persona"), bacon y bacón ("Tocino entreverado y ahumado") ${ }^{8}$. Otras voces o acepciones muy frecuentes presentes en el DEA(A) y ausentes del repertorio académico son bacalao ("bakalao, música de discoteca, de ritmo repetitivo y sin melodía, realizada con sintetizadores") y y babelismo ("Mezcla y confusión de lenguas"). Se incorporan, además, nuevos conceptos y realidades, como baazista ("Del Baaz, movimiento socialista panárabe fundado en Siria en los años cuarenta"), babá ("Pastel de pasta ligera y con pasas, empapado en almíbar con algún licor"), babaco ("Fruto, semejante a la papaya, producido por el árbol americano Carica pentagona"), babuino ("Mono africano..."), o tecnicismos de cierta difusión fuera de los ámbitos específicos, como es el caso de babesiosis (Med. "Infección causada por protozoos del género Babesia).

\subsection{La microestructura del Dea(A)}

Para determinar las características microestructurales del DEA(A) vamos a partir del DEA, y, concretamente, del análisis de los artículos babel, babero, Babia y baca1.

8 El DRAE sí registra beicon ("Panceta ahumada"), y en Enmiendas y adiciones al Diccionario de la Real Academia Española aprobadas por la Corporación, I, Letras A-C (RAE 1998) se propone la adición del artículo bacón como variante de la anterior.

9 Sí está propuesta la adición de esta acepción ("Variedad de música discotequera que tiene un ritmo machacón y ausencia de melodía"), a la voz bacalao. Vid. RAE 1998. 


\section{DEA}

babel ( $t$ con mayúscula, esp en subacep $b$ ) $m o$ (más frec) $f$ Acumulación desordenada y confusa [de perss. o cosas]. I M Molina Jinete 411: En medio del aburrimiento y de la babel de voces que murmuran adormecedoramente en varios idiomas. $Y a$ 8.7.72, 12: Una hora larga estuvo suspendida la sesión para que la ponencia examinase la babel de peticiones hechas. b) Torre de Babel ( $\rightarrow$ TORRE). I A. D. Galicia $S a ́ b .10 .9 .66,12$ : De vez en cuando una escapada a Torremolinos, una "babel" interesantísima. Sampedro Octubre 62: Vea esos dos rascacielos, la Torre de Madrid, el edificio España, Ese es el peligro, esas Babeles, esos monumento de soberbia, esos nidos de extranjerismo, esas imitaciones de lo yanqui.

babero I $\mathrm{m} 1$ Prenda que, colgada del cuello, se pone sobre el pecho a un niño pequeño, para empapar la baba (1a) o para que no se manche al darle de comer. I FReguera Bienaventurados 14: Para el bautizo, la madre se esmeró en hacerle un babero con muchos ringorrangos de puntillas, encajes y perifollos. Abc 15.6.58, 4: Canastilla de París .. Baberos piqué afelpado. b) Prenda que se pone alrededor del cuello para evitar mancharse. I J. Carabias Ya 12.2.75, 6: Incluso los hombres más templados y valientes .. no sienten el menor rubor en confesar que en la antesala del dentista se ponen nerviosos .. Por guapa y agradable que sea la enfermera que les coloca el babero, echarían a correr de buena gana,

2 (hoy raro) Babi (prenda infantil). I ZVicente Mesa 133: Aquel taxista había sido compañero mío de colegio .. Fuimos con el mismo baberito blanco a clase.

3 (Zool) Mancha que tienen algunas aves en la garganta y en el pecho. I Rodríguez Monfragüe 70: Águila culebrera .. En el pecho posee un claro babero o peto igualmente oscuro, que contrasta notoriamente con el blanco del rostro de su plumaje inferior.

4 Prenda que se pone alrededor del cuello y cubre una pequeña parte del pecho, propia de determinados clérigos y religiosos. I Cunqueiro Crónicas 15: Se ataba al cuello el babero planchado de almidón, arrojaba el gorro de dormir, se acomodaba el solideo, y aclarándose con el rapé matutino, saltaba del lecho estruendosamente. CBaroja Baroja 145: Dejando a un lado unos días que fui a una escuela de barrio cerca de casa en Madrid, de frailes de babero blanco .., desde el 
año 21 al 31 fui al mismo centro de enseñanza: el Instituto-Escuela. Delibes Pegar 17: Tuvimos un profesor ejemplar, el hermano Fermín, que, con el tiempo, sin el hábito y el babero, se transformó en José María. b) (col) Hermano de las Escuelas Cristianas. I Umbral País 31.3.83, 19: Clasistas son los jesuitas, los baberos, las jesuitinas y toda la basca.

II loc adj 5 del --. (col) [Hermano] de las Escuelas Cristianas. I Marsé Dicen 142: Media docena de monjas, dos curitas de pueblo, Hermanos del babero con alumnos, un primera comunión vestido de almirante, con chorreras y zapatos de charol y toda la pesca.

Babia ( $t$ b con inicial minúscula). en --, loc adv (col, desp) Sin enterarse de la realidad. Normalmente con el verbo ESTAR. I Torrente Señor 200: Estás un poco en Babia, Carlos .. He oído decir que todos los sabios están un poco en Babia. Laín Universidad 38: Afirmar que la protesta de los estudiantes se debe tan sólo a la acción subversiva de esas minorías expresaría la resuelta vocación de vivir en Babia. b) En actitud distraída o ausente. I CBaroja Baroja 355: Les invitó a merendar cierta poetisa que estaba medio loca .. La poetisa estaba delirante. José, sombrío, y Manolo, en Babia.

baca ${ }^{1} f$ En un automóvil: Portaequipajes instalado sobre el techo. I Cabezas $A b c$ 10.4.75, 53: Vi detenerse un taxi frente a la taberna. Traía sobre la baca esas maletas largas, especiales para transportar los "trastos" taurinos. b) (hoy raro) En un vehículo grande destinado al transporte de viajeros: Espacio situado sobre el techo, con asientos para personas. I Torrente Señor 40: Era día feriado. La baca del coche comenzó a poblarse de aldeanas con cestas de hortalizas y sacos con crías de cerdos.

Los mismos artículos aparecen así en el diccionario abreviado:

$$
\operatorname{DEA}(\mathrm{A})
$$

babel ( $t$ con mayúscula, esp en subacep $b$ ) $m o$ (más frec) $f$ Acumulación desordenada y confusa [de perss. o cosas]. b) Torre de Babel $(\rightarrow$ TORRE).

babero I $\mathrm{m} 1$ Prenda que, colgada del cuello, se pone sobre el pecho a un niño pequeño, para empapar la baba (1a) o para que no se manche al darle de comer. b) Prenda que se pone alrededor del cuello para evitar mancharse. 2 (hoy raro) Babi (prenda infantil). 3 (Zool) 
Mancha que tienen algunas aves en la garganta y en el pecho. 4 Prenda que se pone alrededor del cuello y cubre una pequeña parte del pecho, propia de determinados clérigos y religiosos. b) ( $\mathrm{col}$ ) Hermano de las Escuelas Cristianas.

II loc adj 5 del --. (col) [Hermano] de las Escuelas Cristianas.

Babia ( $t$ b con inicial minúscula). en --, loc adv (col, desp) Sin enterarse de la realidad. Normalmente con el verbo ESTAR. b) En actitud distraída o ausente.

baca ${ }^{1} f$ En un automóvil: Portaequipajes instalado sobre el techo. b) (hoy raro) En un vehículo grande destinado al transporte de viajeros: Espacio situado sobre el techo, con asientos para personas.

\subsection{COMENTARIO}

En la "Introducción" del DEA(A) se dice que es ésta una versión abreviada del Diccionario del español actual, que se propone ofrecer "lo más esencial del contenido de esta gran obra en un solo volumen más manejable" (2000: XI), y, veíamos, también, cómo esta reducción se había hecho suprimiendo los ejemplos tomados del uso real que, con indicación exacta de su procedencia, seguían en aquel a todas las acepciones y locuciones definidas (cfr. 2000: XII). Efectivamente, como puede observarse, se suprime la referencia documental y la cita propiamente dicha, es decir, lo comprendido entre la línea vertical que separa la definición del ejemplo y el comienzo de la siguiente acepción: todo lo demás se mantiene literalmente. Permanece la información normativa ("conjug 1b [averiguar]; tb, semiculto 1d [actuar]", s. v. adecuar), la información sobre la pronunciación ("pronunc corriente /béibi-búm/", s. v. baby boom ) y la información contextual ("[Pers. o animal]", s. v. baboso -sa; "En un automóvil", s. v. baca1). La presencia de estos elementos reduce las posibles deficiencias que pudiera ocasionar para las tareas codificadoras la ausencia de las citas, aunque, en algunos casos, hay breves ejemplos que ilustran, cuando se estima oportuno, algunas acepciones ("El número premiado es el cien", s. v. ciento; "Cierto día vino a verme su padre", s. v. cierto -ta). 


\section{EL DICCIONARIO DE USO DEL ESPAÑOL ABREVIADO [DUE(A)]}

El punto de partida del DuE(A) es la segunda edición, de 1998, llevada a cabo por la Editorial Gredos, del Diccionario de uso del español de María Moliner (la primera edición había visto la luz en los años 1966-1967). Los destinatarios de esta edición abreviada deben de ser los mismos que los de la extensa, aunque de la "Presentación" parece inferirse que aspira a captar un nuevo sector -impreciso- de usuarios: "[...] la autora del Diccionario de uso del español tenía la idea de un diccionario asequible a un público amplio que no necesitara la exhaustividad del gran Due. De ahí que esta edición abreviada, tal como ella la concibió, ocupe un segmento intermedio entre los diccionarios escolares y los de alto nivel".

Como ya son suficientemente conocidos los cambios macro y microestructurales que aparecen como novedad en la segunda edición, nos limitaremos a recordar que a la macroestructura de la primera edición del DuE se le añade para la segunda un 10\%, aproximadamente, de su caudal léxico, por lo que la base de este nuevo DuE(A) supone una reducción en más del $50 \%$ de las aproximadamente 90.000 entradas que contiene la segunda edición de la monumental obra de doña María Moliner; tiene esta versión abreviada unas 40.000 entradas.

\subsection{La macroestructura Del Due(A)}

Para analizar la nomenclatura del DuE(A) vamos a partir de la consideración de la macroestructura de la versión extensa. Registra el DuE en el tramo b-badén, que hemos tomado para este estudio, 124 artículos (Vid. apéndice) que, en su mayoría, comparte con el DraE. Hay 12 entradas -además de los símbolos $B$ y $B a$ - que no contiene el Diccionario académico: babuino, baby-sitter, bacalao ${ }^{2}$, bacalar, bachillerar, bacilariofitas, bacilocoma, backpack, back-up, bacon, bacteriófago, badano, neologismos y tecnicismos de uso frecuente, como lo revela la presencia en el DEA de la mayoría de ellos (babuino, baby-sitter, bacalao ${ }^{2}$, bacilariofitas, back-up, bacon y bacteriófago).

En el DuE(A) se mantiene, según leemos en la "Presentación", lo 
esencial del DuE (definiciones, ejemplos, y frases hechas, indicaciones gramaticales y de uso y los americanismos). "Respecto al léxico -dice-, el recorte necesario para un diccionario de estas características se ha conseguido básicamente reduciendo entradas o acepciones especializadas, algunas con adscripción regional, y otras que no pertenecen al léxico actual. En lo que se refiere a los términos científicos, se han suprimido los restringidos al ámbito científico o técnico [...]" (2000: XI).

El paso del DuE al DuE(A) ha supuesto una reducción, como se indicaba más arriba, de más del 50\%: de 124 entradas del Due, en el tramo b-badén, quedan 55 en el DuE(A). Aunque hay que reconocer que, a pesar del sacrificio de tantas unidades, que reducen notablemente la nomenclatura, la selección realizada ha sido racional y acertada puesto que casi todos los artículos del DuE(A) gozan del respaldo académico (hay apenas media docena de excepciones, es decir, de voces no incluidas en el DRAE: babuino, baby-sitter, bacalao ${ }^{2}$, backpack, back-up y bacon), y son muy escasos los que no registra el DEA (babirusa, bachicha y backpack), espacios que muy bien pudieron ocupar otras voces más rentables.

\subsection{La microestructura del Due(A)}

Como en el caso anterior tomamos los artículos babel, babero, Babia y baca ${ }^{1}$ del diccionario extenso de procedencia:

DuE

babel (del nombre de la torre de que se habla en la Biblia; con mayúsc. o minúsc.; n. calif.) amb. Lugar donde hay gran confusión o *desorden, o donde hablan muchos sin entenderse. sin. Babilonia, TORRE de Babel.

babero $1 \mathrm{~m}$. Prenda que se les pone a los niños por delante, sujeta al cuello, especialmente para que no se manchen mientras se les da de comer. sin. Babador, babera, pechero, peto. 2 (pop.) Vestido fácilmente lavable que se les pone a los niños encima de otro para que éste no se ensucie. sin. *Delantal.

Babia (territorio de las montañas de León; de este nombre se ha hecho derivar la frase "estar en Babia", pero también parece posible que, en ella, "babia" sea un derivado regresivo de "babieca". 
ESTAR EN BABIA. Estar distraído, atontado o ignorante de lo que pasa.

baca '(¿del fr. "bâche"?) 1 f. Espacio en la parte superior de las diligencias y autobuses donde se colocaban los equipajes y en que, a veces, había algunos asientos para viajeros. 2 Armazón instalada sobre el techo de los automóviles para llevar bultos. $\Rightarrow$ Canasta, canastilla, parrilla, portaequipajes.

Así aparecen en la versión abreviada:

\section{DUE(A)}

babel (con mayúsc. o minúsc.; n. calif.) amb. Lugar donde hay gran confusión o *desorden, o donde hablan muchos sin entenderse. TORRE de Babel.

babero $\mathrm{m}$. Prenda que se les pone a los niños por delante, sujeta al cuello, especialmente para que no se manchen mientras se les da de comer.

Babia Estar En BABIA. Estar distraído, atontado o ignorante de lo que pasa.

baca f. Armazón instalada sobre el techo de los automóviles para llevar bultos.

\subsection{COMENTARIO}

Como se informa en la "Presentación", en este diccionario abreviado "se ha prescindido de las etimologías, las formas de expresión y los catálogos porque, si bien son elementos relevantes en el DuE, exceden ampliamente en extensión y contenido los objetivos de esta edición. Se mantienen, en cambio, las palabras y expresiones sinónimas, que no sólo ofrecen alternativas a determinada acepción, sino que en muchos casos clarifican y precisan las definiciones" (2000: XII). Y todo esto es fácilmente comprobable comparando las entradas transcritas más arriba: en el paso del DuE al DuE(A) desaparecen las etimologías, como se observa en el caso de baca1 (“¿del fr. "bâche”?”), los catálogos ("Canasta, canastilla, parrilla, portaequipajes”, s.v. baca). También desaparecen algunos grupos de sinónimos ("Babador, babera, pechero, peto", s.v. babero), o informaciones enciclopédicas de cierto interés ("del nombre de la torre de que se habla en la Biblia", "territorio de las montañas de Le- 
ón; de este nombre se ha hecho derivar la frase "estar en Babia"'”) para la correcta comprensión de algunas definiciones.

Ante las notables distancias existentes, entre los dos repertorios analizados, tanto en lo que se refiere a las nomenclaturas como a las cuestiones microestructurales, cabe preguntarse por qué entre diccionarios de tamaños aproximados [1466 páginas del Due(A) y 1841 del DeA(A)] existen tantas diferencias. Y, por lo pronto, sin entrar en mayores comparaciones nos encontramos con una razón puramente material aunque no exenta de importancia: mientras que en el paso del DeA al DeA(A) se produce una reducción del cuerpo de letra, en el Due(A) el cuerpo de letra aumenta en relación con el del Due, lo que no tiene mucho sentido tratándose de diccionarios -el extenso y el abreviado- dirigidos a los mismos grupos de usuarios. Por esta razón, la media de artículos lexicográficos por página está bastante desequilibrada: 41 en el DeA(A) y 28 en el DuE(A). (El cociente acepción / entrada es muy similar en los dos diccionarios [en torno a $1,4]$.)

\section{CONCLUSIONES}

De los anteriores análisis y reflexiones pueden extraerse las siguientes conclusiones:

1. Las razones por las que se abrevian los diccionarios extensos o generales, y que deben tener presentes los lexicógrafos prácticos, son, fundamentalmente, las siguientes:

a) Para adecuar contenidos a destinatarios distintos a los que se destina la versión extensa (Las llamadas "adaptaciones").

b) Para ofrecer al mismo grupo de usuarios de un diccionario extenso una obra más fácil de manejar en situaciones especiales de consulta. Esta exigencia de la manejabilidad viene dada

b.1. porque los grandes y pesados volúmenes, que son el resultado de extensas nomenclaturas, tienden a frenar, sobre todo cuando son varios, las iniciativas de consulta, $y$ 
b.2. porque la cantidad de información microestructural es inversamente proporcional a la rapidez de la consulta

2. En el proceso de elaboración de un diccionario abreviado caben los siguientes tipos de reducción:

a. Reducción de la macroestructura

b. Reducción de la microestructura

c. Reducción de la macroestructura y la microestructura

Los dos primeros tipos pueden darse de forma independiente cuando el destinatario del diccionario abreviado es el mismo que el del extenso (El DEA[A] es el típico caso de una reducción microestructural). El tercero, la reducción macro y microestructural se da, sobre todo, en las adaptaciones, aunque hay casos, como el del DuE(A), en que se producen las dos reducciones sin que se trate de un verdadero caso de adaptación ${ }^{10}$.

3. Según lo viene haciendo la práctica lexicográfica más solvente, lo conveniente en este proceso de abreviación es que la reducción se haga a costa de aquellos elementos que no son imprescindibles para una comunicación inmediata, tanto desde la perspectiva del emisor (función codificadora) como desde la del receptor (función descodificadora). Los aspectos macroestructurales y microestructurales susceptibles de reducción son los siguientes:

3.1.En la macroestructura, las unidades obsoletas y los términos excesivamente marcados diatópica y diatécnicamente (los localismos y los términos hiperespecíficos). Los marcados diastrática y diafásicamente se deben procurar salvar, pues son muy frecuentes en la comunicación habitual y su presencia es importante para la codificación, concretamente para garantizar la adecuación de

10 Conviene, de todos modos, no perder nunca de vista el verdadero objetivo de la reducción, pues si la versión abreviada que se elabora no va destinada a ningún grupo de usuarios especial sino al mismo grupo estándar de la versión extensa, entonces no tiene mucho sentido aumentar el cuerpo de letra, como hace el DuE(A): si la reducción obedece a razones prácticas de manejabilidad lo que procedería sería la disminución de los tamaños. 
los mensajes a cada situación comunicativa. Hay unidades marcadas que no pertenecen a la lengua general, pues son exclusivas de ciertos dialectos (dialectalismos) o de algunos tecnolectos (tecnicismos), y de éstas puede prescindirse, pero las marcadas diastrática y diafásicamente pueden pertenecer a la lengua general, como ocurre con numerosas voces y acepciones consideradas vulgares, coloquiales, cultas o literarias.

3.2. En la microestructura puede eliminarse la información ortológica, siempre que no exista un gran distanciamiento entre la representación gráfica y la fonética; así por ejemplo, podrá faltar la información ortológica de voces como sillón, caja o lápiz

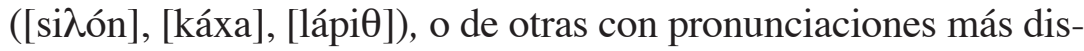
tantes de la escritura, como pescado, examen y cebolla ([peska-

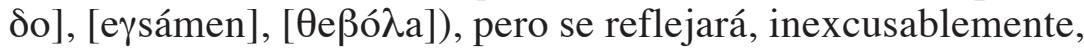
por razones obvias, las de boutique, freudiano y lady ([butík],

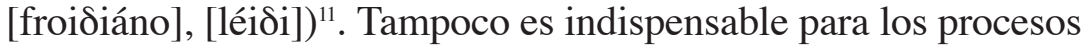
descodificadores y codificadores la información etimológica, por lo que será susceptible de supresión en aquellos casos en que la práctica lexicográfica aconseje la reducción.

Deben tomarse estas conclusiones como recomendaciones que debería seguir la lexicografía para asegurar una mínima calidad en los diccionarios compendiados y, por ende, para garantizar los derechos de los destinatarios. Sin embargo, no pueden prescribirse de modo absoluto, porque, aparte de los factores que hemos tenido en cuenta para justificar la aparición de repertorios léxicos abreviados (la manejabilidad y la adaptación a la comprensión de nuevos grupos de usuarios), es posible que aparezcan otras razones más alejadas de lo estrictamente lingüístico y didáctico y más próximas a asuntos materiales y pecuniarios, de los que tampoco conviene olvidarse, pues el diccionario es, también, un producto comercial. Por eso, habrá que dejar para el momento conveniente la adopción de decisiones relacionadas con la conveniencia o no de eliminar de la macroestructura las raíces prefijas y sufijas, dado el

11 Vid. Humberto Hernández (1998b). 
extraordinario valor productivo de estas unidades, o plantearse si en determinadas circunstancias habría que suprimir o mantener los ejemplos y las citas, y ciertas informaciones enciclopédicas -fuera o dentro de las definiciones.

\section{BIBLIOGRAFÍA}

\section{Diccionarios}

Diccionario didáctico del español Básico (1999): Madrid, SM, $3^{\text {a }}$ ed. [en el texto DDEB].

Diccionario de uso del español actual Clave (1997): Madrid, SM, $2^{\mathrm{a}}$ ed. [en el texto ClaVE].

Moliner, María (2000): Diccionario de uso del español abreviado, Madrid, Gredos [en el texto DuE(A)].

Real ACADEMIa Española (1996): Diccionario escolar, Madrid, Espasa Calpe, 1996 [en el texto DerA].

Real ACADEMia Española (1992): Diccionario de la lengua española, Madrid, Espasa Calpe, $21^{\mathrm{a}}$ ed. [en el texto DRAE].

SeCo, Manuel, Olimpia ANDRÉs y Gabino RAmos (2000): Diccionario del español actual abreviado, Madrid, Aguilar [en el texto DeA(A)].

\section{Estudios}

Alvar EzQuerra, Manuel (1993): "Diccionario y gramática", en Lexicografía descriptiva, Barcelona, Biblograf, pp. 128-129. (Apareció por primera vez en Lingüística Española Actual, IV-2, 1982, pp. 151212).

HERNÁNDEZ, Humberto (1989): Los diccionarios de orientación escolar. Contribución al estudio de la lexicografía monolingüe española, Tubinga, Max Niemeyer.

(1998a): "La lexicografía didáctica del español: aspectos históricos y críticos", en $\mathrm{M}^{\mathrm{a}}$ Teresa Fuentes Morán y Reinhold Werner, eds., Lexicografías iberorrománicas: problemas, propuestas y proyectos, Madrid / Frankfurt, Vervuert / Iberoamericana, pp. 49-79.

—_ (1998b): "En defensa de la ortología. Hacia una fonética normativa del español actual", Español Actual, 70, pp. 37-55.

REAL ACADEMIA EsPaÑola (1998): Enmiendas y adiciones al Diccionario de la Real Academia Española aprobadas por la Corporación, I, 
Letras A-C, (Separata del Boletín de la Real Academia Española, Tomo LXXVII-Cuaderno CCLXXII-Septiembre-Diciembre 1997).

Seco, Manuel (1987): "Problemas formales de la definición", en Estudios de lexicografía española, Madrid, Paraninfo, pp. 15-34. (Se publicó por primera vez en Estudios ofrecidos a Emilio Alarcos Llorach, II, Oviedo, 1978, pp. 217-239, con el título "Problemas formales de la definición lexicográfica").

\section{APÉNDICE \\ (ENTRADAS EN EL TRAMO $b$-badén)}

\section{DRAE}

(127 entradas)

b, baalita, baba, babada, babadero, babador, babaidor, babanca, babanco, babatel, babaza, babazorro(rra), babear, babel, babélico, babeo, babequía, babera, babero, baberol, babi, Babia, babiano(na), babieca, babilar, babilla, babilón(na), babilonia, babilónico, babilonio(nia), babirusa, babismo, bable, baboquia, babor, babosa, babosear, baboseo, babosilla, baboso(sa), babosuelo(la), babucha, babuchero(ra), baca' ${ }^{1}$, baca $^{2}$, bacada, bacalada, bacaladero(ra), bacaladilla, bacalao, bacallao, bacallar, bacanal, bacante, bácara, bacará, bacaray, bácaris, bacarrá, bacelar, bacera, baceta, bachata, bachatear, bachatero(ra), bache ${ }^{1}$, bache ${ }^{2}$, bachear, bacheo, bachicha, bachiche, bachiller ${ }^{1}$, bachiller(ra $)^{2}$, bachilleradgo, bachilleramiento, bachillerar, bachillerato, bachillerear, bachillerejo(ja), bachillería, bacía, báciga, bacilar, bacillar, bacillo, bacilo, bacín, bacina, bacinada, bacinador, bacinejo, bacinero(ra), bacineta, bacinete, bacinica, bacinilla, bacisco, baconiano(na), bacoreta, bacteria, bacteriano(na), bactericida, bacteriemia, bacteriología, bacteriológico(ca), bacteriólogo(ga), bacteriostático(ca), bactriano(na), báculo, bada, badajada, badajazo, badajear, badajo, badajocense, badajoceño(ña), badal $^{1}$, badal ${ }^{2}$, badallar, badalonés(sa), badán, badana, badanado(da), badaza, badea, badelico, badén.

\section{DeA-Dea(A)}

\section{(128 entradas)}

b, baazismo, baazista, baba, babá, babaco, babanca, babar, babeante, babear, babel, babélico-ca, babelismo, babeo, babera, babero, babesiosis, babi, Babia, babianona, babieca, babilla ${ }^{1}$, babilla² ${ }^{2}$ babilonia, babilónico-ca, babilonio-nia, babión-na, bable, babón-na, babor, babosa, babosear, babosería, baboso-sa, babucha, babuino, baby $^{1}$, baby ${ }^{2}$, baby boom, baby boomer, baby crack, baby doll, baby-sitter, baca ${ }^{1}$, 
baca $^{2}$, bacalada, bacaladero-ra, bacaladilla, bacaladillo, bacalao1, bacalao2, bacanal, bacante, bacará, bacareño-ña, bacarrá, baccara, baccarat, bacciforme, baceta, bache ${ }^{1}$, bache $^{2}$, bacheado 1 -da, bacheado ${ }^{2}$, bachear, bacheo, bachiller-ra, bachillerato, bachirresco-ca, bachillería, bacho, bacía, báciga, bacigote, bacilar, bacilariofito-ta, bacilífero-ra, bacillar, bacilo, bacín ${ }^{1}$, bacín²-na, bacinear, bacineja, bacinería, bacinete, bacinica, bacinilla, bacisco, back, backgammon, background, backup, bacon, bacón, bacoreta, bacteria, bacterial, bacteriano-na, bactericida, bactérico-ca, bacteridiano, bacteriemia, bacteriófago, bacteriolisina, bacteriolítico-ca, bacteriología, bacteriológicamente, bacteriológico-ca, bacteriólogo-ga, bacteriopurpurina, bacteriorriza, bacteriostasis, bacteriostático-ca, bactriano-na, baculazo, báculo, badajazo, badajear, badajo, badajocense, badajoceño-ña, badalonense, badalonés-sa, badana, badanas, badanudo-da, badén.

[128]

\section{Due/ Due(A)[+] \\ (124 / 55 entradas)}

b(+), B, Ba, baba(+), babada, babador, babanca, babatel, babaza, babazorro(a), babear(+), babel(+), babélico(a)(+), babeo(+), babera, babero(+), baberol, babi(+), Babia(+), babiano(a), babieca(+), babilar, babilla(+), babilón(a), babilonia, babilónico(a)(+), babilonio(a)(+), babirusa (+), babismo, bable $(+)$, babor(+), babosa $(+)$, babosear(+), baboseo, babosilla, baboso(a)(+), babucha $(+)$, babuino(+), babysitter $(+)$, baca $^{1}(+)$, baca $^{2}$, baca $^{3}$, bacada, bacalada $(+)$, bacaladero $(a)(+)$, bacaladilla o bacaladito $(+)$, bacalao ${ }^{1}(+)$, bacalao ${ }^{2}(+)$, bacalar, bacallar, bacanal $(+)$, bacante $(+)$, bacará, bácara, bacaray, bácaris, bacarrá(+), bacelar, bacera, baceta, bachata, bachatear, bachatero(a), bache ${ }^{1}(+)$, bache ${ }^{2}$, bachear $(+)$, bacheo $(+)$, bachicha $(+)$, bachiche, bachi$\operatorname{ller}^{1}(+)$, bachiller ${ }^{2}$, bachillerar, bachillerato(+), bachillerear, bachillería, bacía $(+)$, báciga, bacilar(+), bacilariofitas, bacillo, bacilo(+), bacilocoma, bacín(+), bacina, bacinada, bacinador, bacinero(a), bacineta, bacinete, bacinica o bacinilla, bacisco, backpack(+), back-up(+), bacon(+), baconiano(a), bacoreta, bacteria(+), bacteriano(a) $(+)$, bactericida $(+)$, bacteriemia, bacteriófago, bacteriología $(+)$, bacteriológico(a)(+), bacteriólogo(a)(+), bacteriostático(a)(+), bactriano(a), baculiforme, báculo(+), bada, badajada, badajazo, badajear, badajo(+), badajocense(+), badajoceño(a), badal ${ }^{1}$, badal $^{2}$, badallar, badalonés(a), badán, badana(+), badano, badaza, badea, badén $(+)$. 